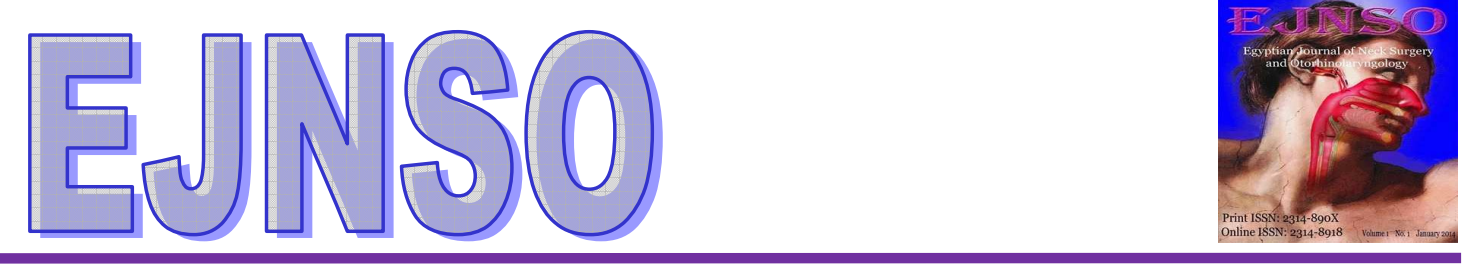

\title{
Prevalence of Dysphagia among Patients at Sohag University Hospital, Southern District of Egypt.
}

\author{
Waleed A.M. Abdelhameed ${ }^{\mathrm{a}}$, Wael A. Ahmed ${ }^{\mathrm{b}}$, Abdel-Mateen M. Abdel-latif \\ a- Associate Professor of Otorhinolaryngology ENT Department, Sohag Faculty of Medicine, Sohag University, Egypt. \\ b- Lecturer of Otorhinolaryngology ENT Department, Sohag Faculty of Medicine, Sohag University, Egypt. \\ c- Professor of Otorhinolaryngology ENT Department, Sohag faculty of Medicine, Sohag University, Egypt.
}

Received: 25/1/2014

Revised: 12/2/2014

Accepted: 4/5/2014

Keywords:

dysphagia

\begin{abstract}
:
Objectives: To study the prevalence of dysphagia and its epidemiology, among patients admitted to the otorhinolaryngology department, Sohag University Hospital along a year, measure the approximate size of the problem in our community, and review the different modalities of treatments given.

Study design: A case series study.

Methods: This study included all patients with dysphagia who had been admitted in our department, between $1^{\text {st }}$ of May 2012 and $30^{\text {th }}$ of April 2013. All patients had been submitted to a thorough history taking of dysphagia, complete ENT and neurologic examination. Investigations included water swallow test, radiologic, endoscopic and laboratory ones.

Results: Among 1861 patients, 346 patients had dysphagia (18.6\%). with a mean age of \pm 25.8 years. The largest age group was below 10 years, Foreign Body swallowing was the main cause in 218 patients (63\%), and number of surgically treated patients was $69 \%$ of total.

Conclusions: Dysphagia represents a main complaint in a significant number of patients admitted to ENT department allover a year. A large number of our patients required tube feeding or gastrostomy, reflecting the increasing underlying chronic and advanced pathologies.
\end{abstract}

\section{1-Introduction:}

Dysphagia is defined as the difficulty or impossibility to swallow liquids, food or medication and can occur during the oropharyngeal or the esophageal phase of swallowing ${ }^{1}$.

In older population, dysphagia has a significant impact on deglutition efficacy and safety. Impairment in deglutition efficacy may cause malnutrition and/ or dehydration while compromised safety increases the risk of aspiration pneumonia $^{2}$.

Approximately $7 \%$ of the population will experience dysphagia with risk equal between genders and incidence increasing with age ${ }^{3}$. The prevalence of dysphagia can reach over $50 \%$ in hospitalized patients with acute illnesses e.g stroke or in nursing home residents aged 65 and older $^{4,5}$.

Signs and symptoms that commonly motivate patients to seek medical care include coughing, choking, drooling, breathlessness, and gurgling between meals, dry oral mucosa, and feeling something is stuck in the throat. By analyzing these, health care providers can identify which phase of the swallowing process is involved ${ }^{6}$. 
According to World Gastroenterology Organisation (WGO) Guidelines 2007.Oropharyngeal dysphagia, in young patients is most often caused by inflammatory, muscle diseases, webs, and rings. In older people, it is usually caused by central nervous system disorders, including stroke, Parkinson disease, and dementia. While three types are most likely to cause esophageal dysphagia:

- Mucosal (intrinsic) diseases, e.g Peptic stricture secondary to gastroesophageal reflux disease, esophageal rings and webs, and tumours.

- Mediastinal (extrinsic) diseases, which obstruct esophagus by direct invasion, e.g lung cancer, or through lymph node enlargement.

-Neuromuscular diseases affecting esophageal smooth muscle and its innervation, e.g Achalasia, postsurgical after fundoplication, antireflux devices.

In addition to Intraluminal foreign bodies as a cause of acute dysphagia ${ }^{7}$.

Foster et al. 2011, proposed a screening and diagnostic algorithm for dysphagia. The first step is based on observation by nurses or caregivers during mealtime, combined with swallow test and oxygen saturation. After positive screening, a clinical validation of dysphagia by speech and language therapist (SLT) is performed, followed by specific evaluation, like Video Fluoroscopic Swallowing Examination (VFSE) or Flexible Endoscopic Evaluation of Swallowing (FEES). After that a comprehensive assessment is done by multidisciplinary team ${ }^{8}$.

On this paper, all the data of patients with dysphagia who had been admitted to the otorhinolaryngology department at Sohag University Hospital was investigated. Sohag University Hospital is a tertiary referral center in Sohag Governorate, a southern district of Egypt (with a population over 4 millions). This research was designed to:

- Study the prevalence of dysphagia and its epidemiology, among patients admitted to our department over a year.

- Measure the approximate size of the problem in our community, and review the different modalities of treatments given.

\section{Patients and Methods:}

This study included all patients who had been presented with dysphagia whether at our outpatient clinics or been admitted in our department, between 1st of May 2012 and 30th of April 2013. They were 346 patients of total number of admitted patients 1861 , with a percentage of $18.6 \%$.

All patients had been submitted to through history taking of dysphagia with concentration on, location, types of foods or liquids, progressive or intermittent, and duration of symptoms. History taking also included any chronic illnesses, medications received.

Complete ENT and neurologic examination had been done. Apart from acute causes of dysphagia, chronic ones have been diagnosed by

- Water swallow test, with the patients drinking $150 \mathrm{ml}$ of water, with recording time taken and number of swallows.

- Flexible Endoscopic Evaluation of Swallowing (FEES) was done in the Phoniatric Unit at Sohag University Hospitals.

- Radiological evaluation with plain X ray \pm Barium swallow.

The diagnosis of patients with Gastro Esophageal Reflux Disease (GERD) was based on:

1)Typical symptoms of heartburn and regurgitation, foreign body sensation in throat which improved with proton pump inhibitors (PPI) treatment and diet modification (100\% of cases).

2) Naso-fiberoptic laryngeal examination revealed interarytenoid granulations which improved with PPI treatment and diet modification (12 patients $70.6 \%$ ). PPI was given at the maximal dose for 8 weeks then maintenance once daily dose (according to guidelines for diagnosis and management put by Katz et al.2013 ).

While diagnosis of Plummer Vinson Syndrome depends on clinical findings, low HB level, and low iron binding capacity, we classified patients according to the cause of dysphagia, age, gender, residence, treatment received. 


\section{3-Results:}

Among 1861 patients who had been admitted to ENT department, Sohag University Hospital, between May 2012 and end of April 2013, 346 patients had dysphagia as main complaint, with a percentage of (18.6\%).

Males represented 204 (59\%) of patients, while females were 142 patients $(41 \%)$. The youngest patient was 1.5 months while the oldest one was 82 years, with a mean of \pm 25.8 years. The largest age group was below 10 years, forming $48.8 \%$ of total (Table 1).

According to their residence, 230 $(66.5 \%)$ patients were from rural areas, while 116 patients $(33.5 \%)$ were from urban areas.

Regarding etiology of dysphagia, foreign body FB swallowing was the main cause in 218 patients, with a percentage of $63 \%$, neoplasms (whether benign or malignant) were the cause in 72 patients $(20.8 \%)$, and third frequent cause was post irradiation in 20 patients $(5.8 \%$; Table 2).

Analyzing the main causes of dysphagia:

\section{(1) FB swallowing:}

Patients below10 years represented the majority with 161 patients, and patients of 50 years old or more were the second frequent group with 22 patients.

The hypopharynx was the main site of impaction, in 212 cases, while esophageal impaction happened in 6 patients only. The nature of FB swallowed is demonstrated in Fig.1.

Seven cases presented with FB swallowing on top of chronic conditions: four cases were on top of Plummer Vinson Syndrome (PVS), two cases were on top of post corrosive strictures and one case was on top of congenital esophageal stricture.

\section{(2) Neoplastic Causes}

Dysphagia due to neoplasia was the cause in 72 patients $(20.8 \%)$. Males were 50 patients $(69.4 \%)$ while female were 22 patients $(30.6 \%)$. Most of the patients were of 60 years old or more (43\%), followed by the patients in their $6^{\text {th }}$ decade of life $(27.8 \%)$, Mean age was 54 years old. Malignant lesions were found in $70(97.2 \%)$ cases, while benign growths had been in 2 cases $(2.8 \%)$.

Regarding the predisposing factors for malignant cases; 50 patients $(71.4 \%)$ were smokers whether positive or negative smokers. 4 patients $(5.7 \%)$ had preexisting PVS. Three patients $(4.2 \%)$ were diagnosed to have associated GERD.

According to the site of the mass, the vast majority of cases were hypopharyngeal or laryngeal cancer with hypopharyngeal extension $(82 \%)$ followed by external compression in (11\%) of cases (table 3 ).

\section{(3) Dysphagia due to neck radiotherapy:}

Twenty patients presented with dysphagia due exposure to neck radiotherapy $(5.8 \%$ of patients included in the study). Males were 15 of them. Most of the patients were of 60 years old or more $(45 \%)$, followed by patients at their $6^{\text {th }}$ decade of life (40\%) with mean age 57.7 years old.

Ten cases received radiotherapy for laryngeal carcinoma, five cases had hypopharyngeal carcinoma, two cases with nasopharyngeal carcinoma, two cases with lymphoma and one case received radiotherapy for thyroid cancer.

\section{(4) Dysphagia due to GERD}

This group was composed of 17 patients ( $4.9 \%$ of total). Females were 15 patients $(88.2 \%)$, and two male patients $(11.8 \%)$. 
Six patients $(35.3 \%)$ were in their $5^{\text {th }}$ decade of life, six patients $(35.3 \%)$ were in their $4^{\text {th }}$ decade while the remaining patients were in younger age groups. The mean age was 40 years old.

\section{(5) Dysphagia due to Plummer Vinson Syndrome}

14 patients (4\% of total) had been presented with PVS. Most of them were females (11 patients; 78.6\%), while male patients were $3(21.4 \%)$. 6 patients $(42.9 \%)$ were in their $5^{\text {th }}$ decade of life, 5 patients $(35.7 \%)$ were in their $4^{\text {th }}$ decade of life, while 3 patients $(21.4 \%)$ were in their $6^{\text {th }}$ decade of life with mean age 41.7 years old. Regarding their residence; 11 patients $(78.6 \%)$ were rural while 3 patients $(21.4 \%)$ were urban.

Eight patients $(57.1 \%)$ of them presented with complications, 4 patients presented with absolute dysphagia due foreign body impaction above the cricopharyngeal narrowing. The other 4 patients had presented with hypopharyngeal carcinoma.

(6) Dysphagia due to neurologic diseases

Twelve patients (3.5\% of total) had dysphagia due to neurologic disorders.Male patients were 9 of them. Four cases $(33.3 \%)$ were60 years old or more, 3 cases $(25 \%)$ were in their $6^{\text {th }}$ decade of life, 2 cases $(16.7 \%)$ werein their $5^{\text {th }}$ decade of life, 2 cases $(16.7 \%)$ were teenagers and 1 case was
1.5 years old. The mean age was 43.6 years old.

Five patients of them (41.7\%) were diagnosed to have cerebro-vascular accident, 3 patients (25\%) were diagnosed to have multiple cranial neuritis, 3 patients (25\%) had generalized myopathy and one patient had encephalitis.

(7) Dysphagia due to post corrosive esophageal stricture

Nine patients hadpresented with dysphagia due post corrosive esophageal stricture.They were 5 females and 4 males.

Vast majority of cases were children below 10 years old ( 7 cases; $77.8 \%$ ), while the other 2 cases; one of them wasin his $4^{\text {th }}$ decade of life and the other in the $7^{\text {th }}$ decade of life. The mean age was 13.7 years.

\section{Patients' outcome:}

Table.4 shows the management given to patients. Cases of malignancy needed the most prolonged management plans. Most of patients preferred radiotherapy \pm chemotherapy rather than the surgical procedures. About way of feeding in our series, 37 cases $(10.7 \%)$ required nasogastric tube feeding, while 14 (4\%) patients required feeding gastrostomy. Ten patients $(2.9 \%)$ of patients included in the study died, 7 of them were diagnosed to have malignant masses and 3 were diagnosed to have recurrent stroke. 
Table 1.Classification of patients according to their age and sex.

\begin{tabular}{|c|c|c|c|}
\hline Age group & \multicolumn{2}{|c|}{ Number } & Percentage \\
\hline \multirow{3}{*}{$<10$ ys } & \multicolumn{2}{|c|}{169} & \multirow{3}{*}{$48.8 \%$} \\
\hline & Male & Female & \\
\hline & $119(70 \%)$ & $50(30 \%)$ & \\
\hline \multirow{3}{*}{$10-19 y s$} & \multicolumn{2}{|c|}{21} & \multirow{3}{*}{$6.1 \%$} \\
\hline & Male & Female & \\
\hline & $9(43 \%)$ & $12(57 \%)$ & \\
\hline \multirow{3}{*}{$20-29 y s$} & \multicolumn{2}{|c|}{10} & \multirow{3}{*}{$2.9 \%$} \\
\hline & Male & Female & \\
\hline & $5(50 \%)$ & $5(50 \%)$ & \\
\hline \multirow{3}{*}{ 30-39ys } & & & \multirow{3}{*}{$5.8 \%$} \\
\hline & Male & Female & \\
\hline & $4(20 \%)$ & $16(80 \%)$ & \\
\hline \multirow{3}{*}{$40-49$ ys } & \multicolumn{2}{|c|}{34} & \multirow{3}{*}{$9.8 \%$} \\
\hline & Male & Female & \\
\hline & $13(38 \%)$ & $21(62 \%)$ & \\
\hline \multirow{3}{*}{$50-59 y s$} & \multicolumn{2}{|c|}{41} & \multirow{3}{*}{$11.8 \%$} \\
\hline & Male & Female & \\
\hline & $21(51 \%)$ & $20(49 \%)$ & \\
\hline \multirow{3}{*}{$>60 y s$} & & & \multirow{3}{*}{$14.7 \%$} \\
\hline & Male & Female & \\
\hline & $33(64 \%)$ & $18(46 \%)$ & \\
\hline
\end{tabular}

Table 2.Classification of patients according to the cause of dysphagia.

\begin{tabular}{|lll|}
\hline F.B Swallow & $218(63 \%)$ \\
\hline Neoplasms & 72 & $(20.8 \%)$ \\
\hline Post irridiation & 20 & $(5.8 \%)$ \\
\hline GERD & 17 & $(4.9 \%)$ \\
\hline PVS & 14 & $(4 \%)$ \\
\hline Neurologic & 12 & $(3.5 \%)$ \\
\hline Post corrosive stricture & $9(2.6 \%)$ \\
\hline Congenital & 2 & $(0.6 \%)$ \\
\hline Psychogenic & 2 & $(0.6 \%)$ \\
\hline $\begin{array}{l}\text { Others } \\
\text { Rheumatological dis. }\end{array}$ & $16 \quad(4.6 \%)$ \\
Spine dis. & $\mathbf{4}$ & \\
Oropharyngeal ulceration & 4 & \\
Angioneuritic edema & 1 & \\
Pharyngeal pouch. & 1 & \\
Achalasia & 1 & \\
\hline
\end{tabular}

Table 3. Site of neoplasms causing dysphagia.

\begin{tabular}{|l|r|r|}
\hline Site & Number & Percentage \\
\hline Hypopharyngeal carcinoma & 30 & $41.7 \%$ \\
\hline $\begin{array}{l}\text { Laryngeal cancer with hypopharyngeal } \\
\text { extension }\end{array}$ & 29 & $40.3 \%$ \\
\hline Esophageal carcinoma & 1 & $1.4 \%$ \\
\hline Gastriccarcinoma & 2 & $2.8 \%$ \\
\hline Tonsillarlymphoma & 2 & $2.8 \%$ \\
\hline External compression: & 8 & $11 \%$ \\
Cervical lymphadenopathy & 4 & \\
Mediastinal mass & 3 & \\
Malignant Thyroid & 1 & \\
\hline
\end{tabular}


Table 4: Treatments modalities provided to the patients

\begin{tabular}{|c|c|c|c|}
\hline Diagnosis & Treatment modality & $\begin{array}{l}\text { Number of } \\
\text { cases }\end{array}$ & Percentage \\
\hline Foreign body swallowing & Endoscopic guided removal. & 218 & $100 \%$ \\
\hline Mass & $\begin{array}{l}\text { patients preferred to receive radiotherapy \&lor } \\
\text { chemotherapy, } \\
\text { patients were advised for surgical procedures but they } \\
\text { missed their follow up, } \\
\text { patients died before any intervention after diagnosis, } \\
\text { Patients chose the surgical option. }\end{array}$ & 55 & $\begin{array}{r}6.9 \% \\
6.9 \% \\
9.8 \%\end{array}$ \\
\hline Post irradiation & $\begin{array}{l}\text { Medical treatment in the form steroids and anti- } \\
\text { edematous }\end{array}$ & 20 & $100 \%$ \\
\hline GERD & $\begin{array}{l}\text { Medical treatment in the form of proton pump } \\
\text { inhibitors }\end{array}$ & 17 & $100 \%$ \\
\hline PVS & $\begin{array}{l}\text { Endoscopic guided dilatation }+ \text { parenteral iron } \\
\text { therapy. }\end{array}$ & 14 & $100 \%$ \\
\hline Neurological & $\begin{array}{l}\text { Medical treatment in the form of neurotonics, steroids } \\
\text { and lor anti- ischemic measures. }\end{array}$ & 12 & $100 \%$ \\
\hline Post corrosive stricture & $\begin{array}{l}\text { cases presented in the acute stage who received } \\
\text { medical treatment with follow up; } \\
\text { Cases presented in the late stage and advised for } \\
\text { endoscopic guided dilatation but they missed their } \\
\text { follow up. }\end{array}$ & 2 & $77.8 \%$ \\
\hline Spine diseases & $\begin{array}{l}\text { Medical treatment in the form of analgesic, anti- } \\
\text { inflammatory + diet modifications. }\end{array}$ & 5 & $100 \%$ \\
\hline Rheumatologic diseases & $\begin{array}{l}\text { Medical treatment in the form of steroids }+1- \\
\text { immunosuppressants. }\end{array}$ & 4 & $100 \%$ \\
\hline Oropharyngealulceration & Medical treatment mainly with steroids. & 4 & $100 \%$ \\
\hline Congenital stricture & $\begin{array}{l}\text { patients were advised for surgical correction after } \\
\text { removal of F.B but they missed their follow up. }\end{array}$ & 2 & $100 \%$ \\
\hline Psychogenic diseases & Medical treatment+ psychotherapy. & 2 & $100 \%$ \\
\hline Angioneuretic edema & $\begin{array}{l}\text { Medical treatment with steroids and anti-allergic } \\
\text { drugs. }\end{array}$ & 1 & $100 \%$ \\
\hline Hypopharyngeal pouch & Was advised for surgical correction but refused. & 1 & $100 \%$ \\
\hline Achalasia & Was advised for surgical correction but refused. & 1 & $100 \%$ \\
\hline
\end{tabular}

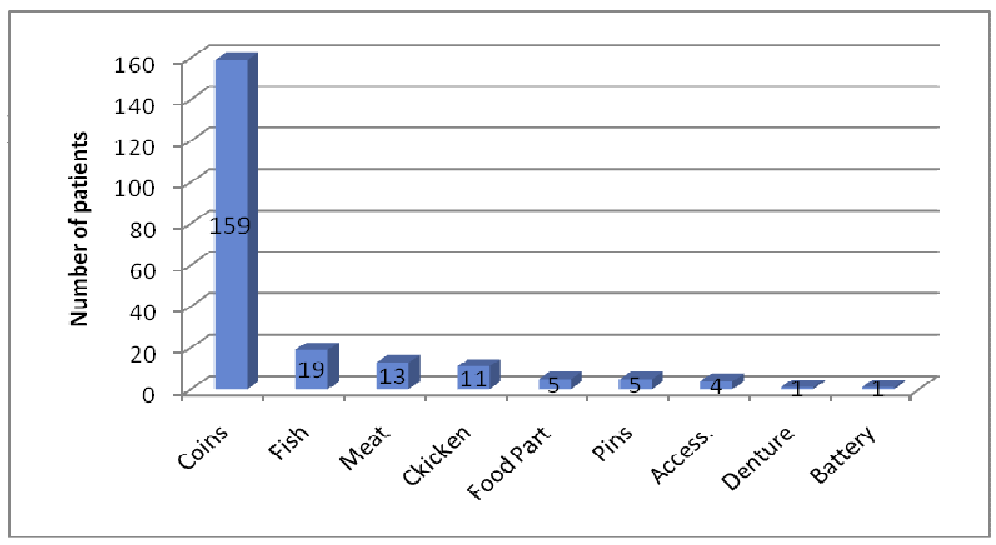

Fig.1: Type of impacted FB.

Data no.5: Food particles, data no.7: Accessories 


\section{Discussion:}

Dysphagia is a common problem. For example, the incidence of dysphagia in acute care centers has been put as high as $33 \%$, and studies in nursing home have shown that $30-40 \%$ of patients have swallowing disturbances ${ }^{7}$.

On the other hand, epidemiological data cannot be provided on a global basis; since the base rate of most diseases that may cause dysphagia tends to differ between countries ${ }^{7}$.

In this study patients presented with dysphagia over a year, constituted $18.6 \%$ (346 patients) of total number of patients admitted to ENT department at Sohag University Hospital. Dysphagia was reported by $16 \%(\mathrm{n}=110)$ in a random sample of 1000 individuals in Sydney, Australia, who were mailed a validated self-report questionnaire to assess dysphagia, from them responders were 672 patients ${ }^{10}$.

In this work, the most affected age group was children below 10 years old $(48.8 \%)$ with mean age of 25.86 years. This is attributed to high number of acute cases specially with FB impaction in our series, generally dysphagia occurs in all age groups but its prevalence increases with age, as the population ages, so does the incidence of conditions that predispose an individual to dysphagia, such as cerebral vascular accident, Parkinson`s disease, dementia, GERD, tumors and strictures ${ }^{11}$.

The current study estimated foreign body swallowing to be the most common cause of dysphagia representing $63 \%$ of cases (218 cases) with male to female ratio about 2:1 and children below 10 years old to be mostly affected (74\% of cases). The most common patient group that unintentionally ingests foreign bodies is children, with most occurring between 6 months and 3 years ${ }^{12,}{ }^{13}$. Coins were the most common FB swallowed $72.9 \%$ of cases.

No much difference regarding the nature of FB swallowed, fish bones represented $8.7 \%$ of cases while meat lumps represented $6 \%$ of cases. In the
United States, meat such as hot dogs, pork, beef, and chicken are the most common foods that result in impaction ${ }^{14}$.

Seven of 56 of our patient who presented with food impaction, had chronic condition, while in study of Lacy $\mathrm{P}$, et al. (1997), most patients (75-100\%) who present with a food impaction have some type of predisposing esophageal pathology ${ }^{15}$.

This work showed that neoplasms are the 2 nd most common cause for dysphagia (20.8\%) with predominance of malignant lesions. About of $71 \%$ of patients were of 50 years old or more. Most of cases were hypopharyngeal or laryngeal with hypopharyngeal extension cancers $(82 \%)$. $71 \%$ of patients were smokers with variant degrees. Oropharyngeal dysphagia was present in $50.6 \%$ of patients with head and neck cancer treated by surgery and radiotherapy or chemotherapy, mostly to solid foods $(72.4 \%)$, studied by GarciaPeris et al. in $2007^{16}$.

Radiotherapy to head and neck region caused dysphagia in $5.8 \%$ of our cases .According to Stone et al.(2003), Patients treated with chemoradiotherapy presented higher rates of dysphagia than the other groupsdue to the side effects of this treatment (xerostomia, mucositis, odynophagia,dysgeusia,etc) $)^{17}$.

Gastro-esophageal reflux in this study represented $4.9 \%$ of cases presented with dysphagia with female predominance $(88 \%)$. A systematic review found that prevalence of GERD to be $10-20 \%$ of the western world with a lower prevalence in Asia $^{18}$. Sharma et al, found that the prevalence of GERD was $16.2 \%$ in his study upon 4039 employees of a tertiary care center in India $^{19}$.On other side,Plummer Vinson Syndrome represented $4 \%$ of cases with female predominance $78.6 \%$ and $78.8 \%$ of them were in their 4th and 5th decades of life. This number reflects low socioeconomic levels and nutritional deficiencies of our patients.

In a series of 1000 consecutive patients who underwent a cineradiographic examination of the hypopharynx and cervical esophagus, webs were found in 
$5.5 \%$ of the cases but only six patients had dysphagia attributable to the webs, and none of the patients fulfilled the criteria for Plummer-Vinson syndrome ${ }^{20}$.

Neurologic diseases represented 3.5\% of causes of dysphagia in this study with male predominance $(75 \%)$. About $58.5 \%$ of patients were 50 years old or more. This small number doesn't represent the actual size of this category, as many patients are managed in other departments, or care homes. In cerebrovascular diseases, divergent prevalence of dysphagia was reported between 20$50 \%^{21,22}$.

Corrosive swallowing represented $2.6 \%$ of causes of dysphagia in this study with most cases $(77.8 \%)$ children below 10 years old. The most common problem worldwide can lead to stricture formation in small children is ingestion of caustic liquids from around the household that range from bleach to hair care products ${ }^{23}$.

As regard treatment provided, 239 patients $(69 \%)$ underwent surgery, this reflects high number of acute cases in our series. $14.7 \%$ of patients needed assisted feeding through nasogastric tube or gastrostomy, this shows significant number of chronic cases in our study, while in the study of Garcia-Peris et al.on 87 patients with head and neck cancer treated with surgery and radiotherapy or chemotherapy, only 2 patients required tube feeding ${ }^{16}$.

\section{Limitations:}

This study gives approximate values about different causes of dysphagia in our locality, many causes may be underestimated. To get a more definite number about prevalence of dysphagia in our community, a survey should include all hospitals in Sohag governorate, or cover larger number of people to represent whole population.

\section{Conclusions:}

- Dysphagia represents a significant number of patients admitted to ENT department over a year.

- Foreign body swallowing is the main cause of dysphagia in our series, so this raises number of surgically treated patients to $69 \%$ of total.

- Significant number of our patients required tube feeding or gastrostomy, reflecting the increasing underlying chronic and advanced pathologies.

\section{Acknowledgments:}

The authors would like to thank Dr. Engy N. Henry for her help and extreme efforts in the collection of data.

\section{References:}

1. Cabre M, Serra-Part M, Palomera E, etal. Prevalence and prognostic implications of dysphagia in elderly patients with pneumonia. Age Ageing.2010; 39:39-45.

2. Clave P, Verdaguer A, Arreola V. Oropharyngeal dysphagia in elderly. Med Clin.2005; 124:742-748.

3. Wieseke A, Bantz D, Siktberg L, Dillard N. Assessment and early diagnosis of dysphagia. Geriatric Nursing 2008; 29:376-383.

4. Martino R, Foley N, Bhogal S, et al. Dysphagia after stroke: Incidence, diagnosis and pulmonary complications. Stroke 2005; 36:27562763.

5. Lin LC, Wu SC, Chen HS, et al. Prevalence of impaired swallowing in institutionalized older people in Taiwan.J Am GeriatrSoc 2002;50:1118-1123.

6. Blackington E, McCormick T, Wilson $\mathrm{B}$, et al. Oropharyngeal dysphagia in the elderly: Identifying and managing patients at risk. Adv Nurse Practit 2001; 9:42-48.

7. Malagelada J, Bazzoli F, Elewaut A, et al. Dysphagia. WGO Practice Guidelines 2007:1-14.

8. Foster A, Samaras N, Gold G, Samaras D. Oropharyngeal dysphagia in older adults: A review. EurGer Med 2011; 2:356-362. 
9. Katz PD, Gerson LB, Vela MF. Guidelines for the diagnosis and management of Gastroesophageal Reflux Disease. Am J Gastroenterol 2013;108:308-328.

10. Eslick GD, Talley NJ. Dysphagia: epidemiology, risk factors and impact on quality of life - a population-based study. Aliment PharmacolTher. 2008; 27(10):971-979.

11. US Census Bureau. Longevity and health. 2005. Available at www.census.gov/prod/2006pubs. pdf.p.35-82.Cited March 2007.

12. Webb WA. Management of foreign bodies in the upper gastrointestinal tract.Gastroenterology 1988; 94:204216.

13. Chen M, Beierle E. Gastrointestinal foreign bodies.Pediat Ann 2001;30:736-742.

14. Lin H, Lee S, Chu H, et al. Emergency endoscopic management of dietary foreign bodies in the esophagus. Am $\mathbf{J}$ Emerg Med 2007;25:662-665.

15. Lacy P, Donnelly M, McGrath J, et al. Acute food bolus impaction: aetiology and management. J laryngolOtol 1997;111:1158-1161.

16. Garcia-Peris P, Paron L, Velasco C, et al. Long term prevalence of oropharyngeal dysphagia in head and neck cancer patients: Impact on quality of life. Clinical Nutrition 2007;26:710717.
17. Stone H, Coleman C, Anscher M, et al. Effects of radiation on normal tissue consequences and mechanisms. Lancet Oncol 2003;4(9):529-536.

18. Dent J, El-Serag H, Wallander M, et al. Epidemiology of GERD. A systematic reviw.Gut 2005;54:710717.

19.Sharma PK, Ahuja V, Madan K, Gupta S, Raizada A, Sharma MP.

Prevalence, severity, and risk factors of symptomatic gastroesophageal reflux disease among employees of a large hospital in Northern India.Indian $\mathbf{J}$ Gastroenterol. 2011; 30(3): 128-134.

20. Nosher JL, Campbel WL, Seaman WB.The clinical significance of cervical esophageal and hypopharyngeal webs.Radiology.1975;117:45-47.

21. Falsetti P, Acciai C, Palilla R, et al.Oropharyngeal dysphagia after stroke, incidence, diagnosis, and clinical predictors in patients admitted to neurohabilitation unit. J Stroke Cerebrovas Dis 2009;18:329-335.

22. Remesso G, Fukujima M, Chiappeta $D$, et al. Swallowing disorders after ischemic stroke. ArqNeuropsiquiatr. 2011;69:785-789.

23. Khan KM.Endoscopic management of strictures in pediatrics. Techniques in Gastrointestinal Endoscopy 2013;15:25-31. 